\title{
Vanishing White Matter Disease: A Case Report
}

\author{
MOHAMMAD IMNUL ISLAM ${ }^{1}$, SKAZIMUL HOQUE ${ }^{2}$, MD TARIQUL ISLAM ${ }^{1}$, NARAYAN CHANDRA SAHA ${ }^{3}$, \\ ABDUL. MATIN² ${ }^{2}$ AKM MATIUR RAHMAN² ${ }^{2}$ ABU SADAT MD. SALEH ${ }^{4}$
}

\section{Introduction:}

Vanishing white matter disease (VWM) is one of the most prevalent inherited childhood leucoencephalopathies. The disease is variably called Myelinopathia Centralis Diffusa. Childhood ataxia and diffuse central nervous system hypomyelination are the common findings. The disease is characterized by chronic progressive and episodic deterioration with ataxia, spasticity and optic atrophy. ${ }^{1}$ VWM is caused by mutation in any of the five genes encoding the subunits of eukaryotic translation initiation factor elF2B. ${ }^{2,3}$ The disease has an autosomal recessive mode of inheritance. The cause of the disease is unknown. Previously it was known that there is no biochemical marker for this disease, ${ }^{4}$ but recently analysis of body fluids has revealed only a few biochemical markers for VWM. The first marker found was a consistent elevation of cerebrospinal fluid glycine concentrations with an elevated ratio of cerebrospinal fluid to plasma glycine concentrations. ${ }^{5} \mathrm{~A}$ decreased cerebrospinal fluid concentration of asialotransferrin is a recently identified biomarker for VWM. ${ }^{6,7}$

\section{Case Report:}

Rudru, eight months old male child, first issue of nonconsanguineous parents, hailing from Dhaka presented with sudden jerky movement of single limb associated with stiffness of whole body for one month and fifteen days which had been gradually increasing and there was developmental deterioration for three months. He had two episodes of fever and maculopapular rash four months back. But there was no history of head trauma or contact with TB patients. His birth history was uneventful and he was immunized as per EPI schedule. He was on complementary feeding.

1. Assistant Professor, Department of Pediatrics. Bangabandhu Sheikh Mujib Medical University, Dhaka

2. Assistant Professor, Department of Pediatrics. Dhaka Medical College and Hospital, Dhaka

3. Associate Professor, Department of Pediatrics. Dhaka Medical College and Hospital, Dhaka

4. Postgraduate trainee. Department of Pediatrics. Dhaka Medical College and Hospital, Dhaka.

Correspondence: Dr. Mohammad Imnul Islam.
On examination the child was ill looking, mildly pale, BCG mark was present. His weight was $8 \mathrm{~kg}$, supine length was $73 \mathrm{~cm}$ (within normal limit), and OFC was $42 \mathrm{~cm}$ (below $5^{\text {th }}$ percentile). His motor functions, bulk,
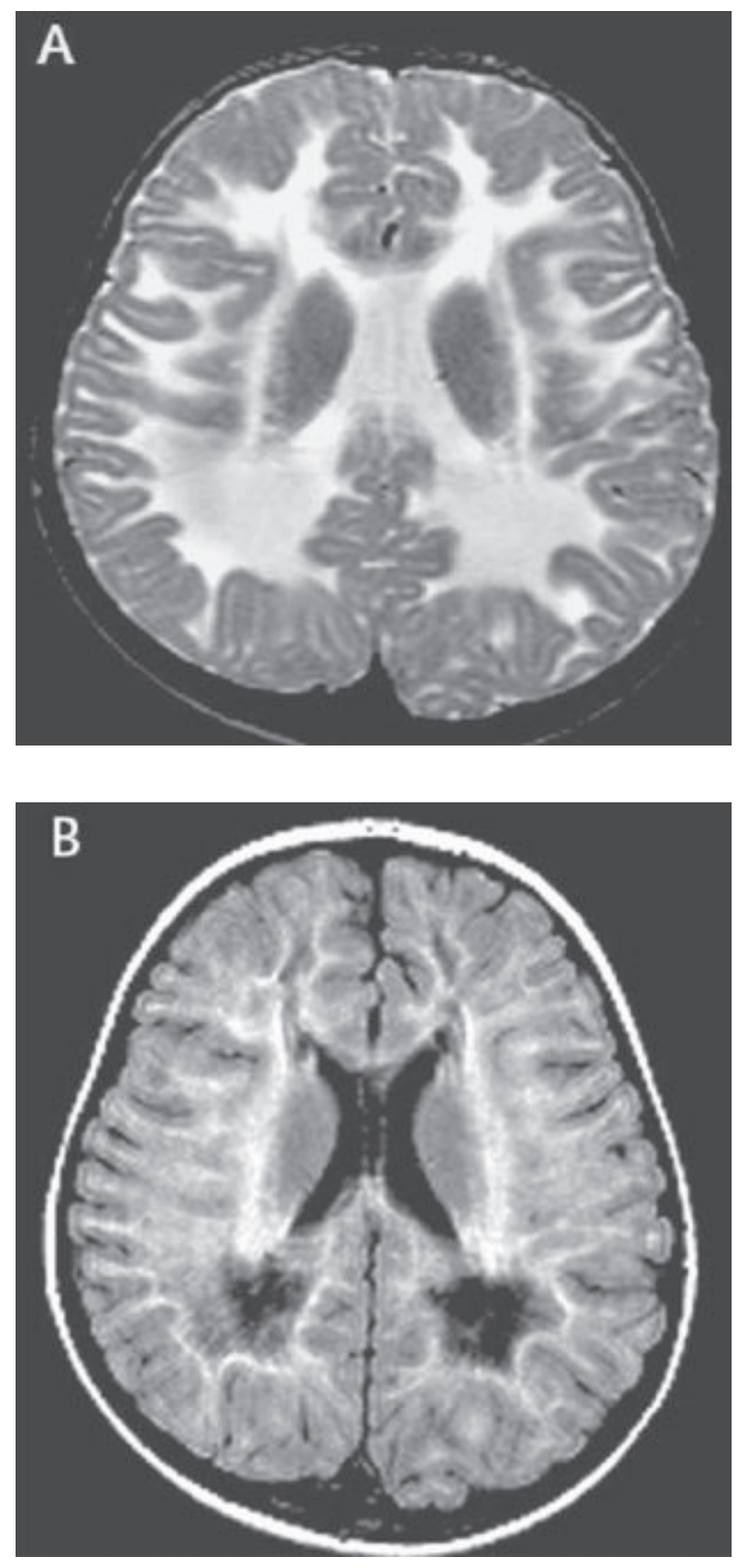

Fig: $A$ \& B MRl of Brain showed an abnormal signal of cerebral white matter 
power was normal but tone was increased. All reflexes of both upper and lower limbs were exaggerated, plantar was extensor and ankle clonus was also present bilaterally. Co-ordination and gait could not be elicited. His sensory functions and cranial nerve revealed intact. He was developmentally delayed as he was not able to sit. Other system revealed normal findings. His blood picture was normal. MRI of brain showed an abnormal signal of cerebral white matter, $U$ fibers were spared, rarefaction and cystic degeneration of white matter. Considering history, clinical examinations and investigation reports this case was diagnosed as a case of Vanishing white matter (VWM) disease. There is no specific treatment for VWM; counseling was done with the parents regarding the etiology, progression and outcome of the disease. Advice was given to avoid stress situations and head trauma and to take liberal use of antibiotics, antipyretics and vaccination. He was also advised regular follow-up for progression of the condition.

\section{Discussion:}

The classical and most common variant of Vanishing white matter disease has its onset in childhood, at age 2-6 years ${ }^{8,9}$ though this disease may have an early infantile or antenatal onset. ${ }^{10-12}$ that had happened in our patient. The first time this disease was documented in 1962 when Eickle studied a 36 year old woman. ${ }^{1}$ In 1993-94, Dr. Hanefeld and Dr. Schiffmann and their colleagues identified the disease as childhood-onset progressive leukoencephalopathy. ${ }^{10}$ It is characterized by chronic progressive neurological deterioration with cerebellar ataxia, usually less prominent spasticity and relatively mild mental decline.$^{8,9}$ Epilepsy is common. Characteristically, there are additional episodes of major and rapid deterioration following minor head trauma and especially febrile infections ${ }^{9,11}$. In our case the patient had a chronic progressive neurological abnormal sign as a jerky movement, but he had no epilepsy. His mental function and ataxia could not be elicited due to too younger age. Optic atrophy with loss of vision may occur, ${ }^{8}$ but that was not present in our patient. The baby had not a history of acute frightening that recently has been reported as another provoking factor. ${ }^{13} \mathrm{MRI}$ of the brain is usually diagnostic in VWM. It shows an abnormal signal of all or almost all cerebral white matter with relatively spared U-fibers in some cases and progressive rarefaction and cystic degeneration of the affected white matter that is replaced by fluid. ${ }^{9,10,14}$ These features are almost consistent with the MRI of our case. No test was done to identify biomedical marker relevant to this disease.

\section{Conclusion:}

Vanishing white matter disease is an intriguing disease, both from a clinical and molecular perspective. There is no specific treatment for VWM. Avoidance of stress situations known to provoke deterioration in VWM patients is essential. Liberal use of antibiotics and antipyretics, vaccinations, and abstinence of contact sports are simple but important measures. However, they are not sufficient to prevent onset or progression of the disease. The most important consequence of research findings of the last 5 years probably is that prenatal diagnosis has become available for families as soon as the disease-causing mutations in the index patient have been identified.

\section{References:}

1. Vander Knaap MS, Pronak JC, Scheper GC. Vanishing white matter disease. The lancet Neurology 2006; 5(4): 413-23.

2. Vander Knaap MS, Pronak JC, Andrea AM, Cees BM, Ruud BH, Peter AJ Leegwater, et al. Mutations in each of the five subunits of translation initiation factor elF2B can cause leukoencephalopathy with vanishing white matter. Ann Neurol 2002; 51(2): 264-70.

3. Labauge P, Fogli A, Niel F, Rodriguez D. CACH/ VWM syndrome and leucodystrophies related to EIF2B mutations. Rev Neurol. 2007;163:7939.

4. Schiff mann R, Moller JR, Trapp BD, Edward MK, Robert GF, Norman WB. Childhood ataxia with diffuse central nervous system hypomyelination. Ann Neurol 1994;35(3): 33140.

5. Vander Knaap MS, Wevers RA, Kure S, Jaeken J, Verhoeven NM, Gabreel Fons JM, et al. Increased cerebrospinal fluid glycine: a biochemical marker for a leukoencephalopathy with vanishing white matter. J Child Neurol. 1999;14(11): 728-31.

6. Vanderver A, Schiff mann R, Timmons $M$, Katherine A, Hathout Y, Fabris D, et al. Decreased asialotransferrin in cerebrospinal fluid of patients with childhood ataxia and central nervous system hypomyelination or vanishing 
white matter disease. Clin Chem 2005; 51(11): 2031-42.

7. Dastych M, Gottwaldova J, Pohludka M, Prikryl $P$, Benovoska $M$. Determination of asialotransferrin in the cerebrospinal fluid with the HPLC method. Scand J Clin Lab Invest 2010 ;70(2): 87-91.

8. Hanefeld F, Holzbach U, Kruse B, Wilichowski E, Christen HJ, Frahm J. Diffuse white matter disease in three children: an encephalopathy with unique features on magnetic resonance imaging and proton magnetic resonance spectroscopy. Neuropediatrics 1993;24(5): 244-8.

9. Vander Knaap MS, Barth PG, Gabreels FJ, Franzoni E, Begeer JH, Valk J, et al. A new leukoencephalopathy with vanishing white matter. Neurology 1997; 48:845-55.

10. Vander Knaap MS, Kamphorst W, Barth PG, Gut $\mathrm{E}$, Valk J. Phenotypic variation in leuko- encephalopathy with vanishing white matter. Neurology. 1998; 51:540-47.

11. Fogli A, Dionisi-Vici C, Deodato F, Bartuli A, Bertini E, Boespflug-Tanguv O. A severe variant of childhood ataxia with central hypomyelination/ vanishing white matter leukoencephalopathy related to EIF21B5 mutation. Neurology 2002; 59: 1966-8.

12. Vander Knaap MS, Van Berkel CGM, Herms J, Coster RV, Baethmann M, Naidu S, et al. elF2B related disorders: antenatal onset and involvement of multiple organs. Am J Hum Genet 2003;73(5): 1199-07.

13. Vermeulen G, Seidl R, Mercimek-Mahmutoglu S, Vander Knaap MS, Gert CS, Jan JR et al. Fright is a provoking factor in vanishing white matter disease. Ann Neurol 2005; 57(4): 560-3.

14. Labauge P. Magnetic resonance findings in leucodystrophies and MS. Int MS J 2009 ;16(2): 47-56. 